\title{
SUSCEPTIBILIDADE A DESERTIFICAÇÃO PARA O ESTADO DE PERNAMBUCO
}

\author{
Michelle Adelino Cequeira ${ }^{1}$ \\ Flávia Mazzer Rodrigues ${ }^{2}$ \\ Gleymerson Vieira Lima de Almeida ${ }^{3}$
}

Resumo: A desertificação pode ser compreendida como um processo de degradação das terras áridas, semiáridas e subúmidas secas, resultante de variações climáticas e atividades humanas. Aspectos mais danosos recaem, principalmente, sobre a redução da fertilidade e capacidade de produção das terras, por se tratar, muitas vezes, de um quadro irreversível. Para tanto, uma das formas mais úteis e aplicadas para estudos de verificação da susceptibilidade a desertificação é através do cálculo do Índice de Aridez (IA). Assim, o presente trabalho se utiliza de tal metodologia para verificação da distribuição espacial do índice de aridez para o Estado de Pernambuco, ao longo do período de 1993 a 2016 com o auxílio de sistema de informação geográfica. Observou-se que no período de 2013 a 2016 o Estado de Pernambuco sofreu as maiores reduções dos valores do índice de aridez, assim como em suas respectivas pluviosidades. Destaque para o município de Itacaruba que apresentou índice de aridez de 6,1, sendo o menor valor registrado quando comparado com os 185 municípios e a maior susceptibilidade a desertificação com grau de 11,25. O município de Jatobá, apresentou o menor valor pluviométrico na série histórica de 23 anos analisados, com uma média anual de $263,76 \mathrm{~mm}$. Esses resultados devem subsidiar estudos posteriores e permitir a elaboração e implantação de adequado planejamento ambiental.

Palavras-chave: Nordeste. Seca. Geoprocessamento. Caatinga. Interpolação.

\section{SUCEPTIBILITY DESERTIFICATION FOR THE PERNAMBUCO STATE}

Abstract: Desertification can be understood as a process of degradation of arid, semi-arid and dry sub-humid lands, resulting from climatic variations and human activities. Most damaging aspects fall mainly on the reduction of fertility and the production capacity of the land, as it is often an irreversible situation. For this, one of the most useful and applied ways for studies to verify the susceptibility to desertification is through the calculation of the Aridity Index (Al). Thus, the present work uses this methodology to verify the spatial distribution of the aridity index for the State of Pernambuco, from 1993 to 2016 with the help of a geographic information system. It was observed that in the period from 2013 to 2016 the State of Pernambuco suffered the greatest reductions in the values of the aridity index, as well as in their respective rainfall. Highlight for the municipality of Itacaruba, which presented an aridity index of 6.1 , with the lowest value recorded when compared to 185 municipalities and the highest susceptibility to desertification with a grade of 11.25. The municipality of Jatobá, presented the lowest rainfall in the historical series of 23 years analyzed, with an annual average of $263.76 \mathrm{~mm}$. These results should

\footnotetext{
${ }^{1}$ Universidade Federal de Alagoas, Campus de Engenharias e Ciências Agrárias, Rio Largo, Brasil, michelle.cerqueira@ceca.ufal.br, https://orcid.org/0000-0002-4090-1204

2 Universidade Federal de Minas Gerais, Instituto de Ciências Agrárias, Montes Claros, Brasil, flamazzer@ufmg.br, https://orcid.org/0000-0001-5520-1844

${ }^{3}$ Escola Técnica Estadual de Pernambuco, Área de Recursos Naturais - Agroecologia, São José do Belmonte-PE, Brasil, gleymersonalmeida@hotmail.com, https://orcid.org/0000-0002-7705-7940
} 
support further studies and allow the preparation and implementation of adequate environmental planning.

Keywords: Northeast. Dry. Geoprocessing. Caatinga. Interpolation.

\section{SUSCEPTIBILIDAD LA DESERTIFICACIÓN PARA EL ESTADO DE PERNAMBUCO}

Resumen: La desertificación puede entenderse como un proceso de degradación de tierras áridas, semiáridas y subhúmedas secas, como resultado de variaciones climáticas y actividades humanas. Los aspectos más perjudiciales recaen principalmente en la reducción de la fertilidad y la capacidad de producción de la tierra, ya que a menudo es una situación irreversible. Para eso, una de las formas más útiles y aplicadas para que los estudios verifiquen la susceptibilidad a la desertificación es a través del cálculo del Índice de Aridez (AI). Por lo tanto, el presente trabajo utiliza esta metodología para verificar la distribución espacial del índice de aridez para el Estado de Pernambuco, de 1993 a 2016 con la ayuda de un sistema de información geográfica. Se observó que en el período de 2013 a 2016, el Estado de Pernambuco sufrió las mayores reducciones en los valores del índice de aridez, así como en sus respectivas precipitaciones. Destacado para el municipio de Itacaruba, que presentó un índice de aridez de 6.1, con el valor más bajo registrado en comparación con 185 municipios y la mayor susceptibilidad a la desertificación con un grado de 11.25. El municipio de Jatobá, presentó la menor precipitación en la serie histórica de 23 años analizados, con un promedio anual de $263.76 \mathrm{~mm}$. Estos resultados deberían respaldar más estudios y permitir la preparación e implementación de una planificación ambiental adecuada.

Palabras clave: Noreste. Seco. Geoprocesamiento. Caatinga. interpolación.

\section{Introdução}

O clima é formado por vários elementos como radiação solar, precipitação pluviométrica, temperatura do ar, umidade do ar, vento, pressão atmosférica, evaporação entre outros, onde é importante analisar a ação desses no ambiente. $O$ Brasil, devido a configuração e extensão do seu território, possui diferenciados regimes de precipitação e temperatura com características distintas e regionais (OLIVEIRA et al., 2014).

Contudo, as informações das condições climáticas de uma área são necessárias para que se possam planejar estratégias, que busquem o manejo adequado dos recursos naturais, e implementação das práticas agrícolas viáveis para o ambiente e a produtividade agropecuária (COSTA NETO et al., 2014) principalmente em áreas consideradas suscetíveis à desertificação.

De acordo com a Convenção das Nações Unidas de Combate à Desertificação, a desertificação é definida como um processo de degradação ambiental causada pelo manejo inadequado dos recursos naturais nos espaços 
áridos, semiáridos e subúmidos secos, que compromete os sistemas produtivos das áreas susceptíveis, os serviços ambientais e a conservação da biodiversidade. No Brasil são 1.480 municípios susceptíveis a esse processo que pode ser causado pelo homem ou pela própria natureza e agravados pelas questões climáticas (BRASIL, 1998).

A última grande avaliação sobre o estado da desertificação no mundo foi elaborada pelo Programa das Nações Unidas para o Meio Ambiente (PNUD) em 1991. Nessa época, a desertificação já afetava diretamente 3,6 bilhões de hectares e 1/6 da população mundial (UNEP, 1992).

As áreas semiáridas do Brasil, com $980.711 \mathrm{~km}^{2}$ e a aproximadamente $60 \%$ da região Nordeste, estão mais susceptíveis as consequências da elevação da temperatura. Segundo a ONU, são as áreas mais susceptíveis para desertificação e em termos de Estados, pode-se listar Ceará, Piauí, Rio Grande do Norte, Paraíba, Pernambuco, Alagoas, Sergipe, Bahia e Minas Gerais (DOMINGUES et al., 2011).

Contudo, o Nordeste do Brasil é marcado pela ocorrência de grandes e prolongados eventos de secas, com distintos graus de severidade, ocasionados em decorrência da irregularidade espacial e temporal da precipitação, na qual é concentrada em um único período de três a cinco meses no ano, e pelo elevado potencial para evaporação da água em função da grande disponibilidade de energia solar e altas temperaturas durante todo o ano (SOUZA, 2013).

O Centro de Gestão e Estudos Estratégicos destaca que em Pernambuco, a concentração das áreas degradadas situa-se na região centro sul do Estado. Manchas esparsas se encontram distribuídas por toda a área. $O$ total de área degradada mapeada atinge $3.286,42 \mathrm{~km}^{2}$. No Estado, encontra-se o Núcleo de Desertificação de Cabrobó, indicado por Vasconcelos Sobrinho e confirmado pelo PAN-Brasil (CGEE, 2016).

Observa-se uma preocupação mundial com 0 aumento das áreas desertificadas, uma vez que os impactos ocasionados pela degradação nos recursos da terra são reconhecidos como um problema ambiental global (LANFREDI et al., 2015). Para essas áreas frágeis, torna-se necessário propor estratégias que permitam o monitoramento contínuo e preciso, visando não somente avaliar a vulnerabilidade, mas também frear o processo de degradação (IBAÑEZ et al., 2014; ZDRULI, 2014). 
Para tanto, a forma de entender e diagnosticar as possíveis causas e consequências tem sido o estabelecimento de indicadores dos processos (MATALLO JÚNIOR, 2001).

Um dos indicadores é a determinação do índice de aridez, considerado de grande precisão na determinação das áreas vulneráveis à desertificação, devido ao fato de a ocorrência deste processo se limitar a áreas secas, e o cálculo deste índice indica exatamente esta condição climática (SAMPAIO; SAMPAIO, 2002).

Ressalva-se que em 1977 este índice foi aplicado no Plano de Ação de Combate à Desertificação das Nações Unidas (SCHENKEL; MATALLO JÚNIOR, 2003).

Portanto, aridez é um atributo climático que relaciona a insuficiência de precipitação indispensável para manter uma vegetação (AMARAL et al., 2014), conjuntamente com a utilização do sensoriamento remoto que possibilita uma análise espacial e temporal deste processo.

Deste modo, informações sobre a aridez são imprescindíveis para elucidar as características da paisagem e possibilitar a determinação de medidas políticas e de gestão indispensáveis a utilização racional dos recursos hídricos em muitas regiões, principalmente na semiárida.

Diante do exposto, o objetivo deste trabalho consiste em analisar a susceptibilidade à ocorrência da desertificação no Estado de Pernambuco, utilizando-se sistema de informação geográfica.

\section{Material e Métodos}

\section{Caracterização da área de estudo}

A área de estudo corresponde ao Estado de Pernambuco que localiza- se no Nordeste brasileiro, entre as latitudes $07^{\circ} 32^{\prime} 00^{\prime \prime}, 08^{\circ} 55^{\prime} 30^{\prime \prime} \mathrm{S}$ e paralelos $34^{\circ} 48^{\prime} 35^{\prime \prime}$, 4119'54" W., apresentando uma área territorial de 98.938 km² que corresponde a 6,3\% da Região Nordeste (CEPED; UFSC, 2012).

O Estado de Pernambuco, com uma população de 8.796.032 habitantes apresenta uma densidade demográfica de 89,60 hab/ $\mathrm{Km}^{2}$. Na capital Recife, a densidade é de $7.037,61$ hab/km², com uma população de 1.537 .704 habitantes (IBGE, 2011).

O Estado de Pernambuco limita-se ao norte, com os Estados da Paraíba e do Ceará; a oeste, com o Piauí; ao sul, com a Bahia, tendo o Rio São Francisco como divisor, e com Alagoas; e a leste, com o Oceano Atlântico. Como observado na 
Figura 01, o Estado possui 184 municípios, divididos em cinco mesorregiões: Mesorregião do São Francisco Pernambucano, no sudoeste do estado; Mesorregião do Sertão Pernambucano, no nordeste do estado; Mesorregião do Agreste Pernambucano, no centro; Mesorregião da Mata Pernambucana, no leste; e a Mesorregião Metropolitana do Recife, no extremo leste do estado. A cidade de Recife, situada nesta última mesorregião, é a capital do Estado de Pernambuco. O Distrito Estadual de Fernando de Noronha, que fica a $545 \mathrm{~km}$ de distância de Recife, também pertence a este estado (Figura 01), (CEPED; UFSC, 2012).

O Estado de Pernambuco possui cerca de $70 \%$ do seu território inserido no "polígono das secas", região definida pela SUDENE (Superintendência do Desenvolvimento do Nordeste) delimitada pelas isoietas de $800 \mathrm{~mm}$ de chuvas anuais, sendo assim frequentemente afetada por secas severas (CEPED; UFSC, 2012).

No Sertão, setor semiárido, predomina o clima tropical árido e semiárido, em que as chuvas concentram-se, principalmente, nos quadrimestres janeiro/abril e fevereiro/maio. No Agreste Pernambuco, região de transição entre o Sertão e a Zona da Mata, predomina o clima tropical semiárido e subúmido. As chuvas nesta região concentram-se principalmente nos quadrimestres março/junho e abril/julho, destacando-se algumas áreas mais úmidas - os brejos - resultantes de uma pluviosidade mais abundante (BANCO DO NORDESTE, 2001).

Figura 01 - Localização das Mesorregiões no Estado de Pernambuco, Brasil.

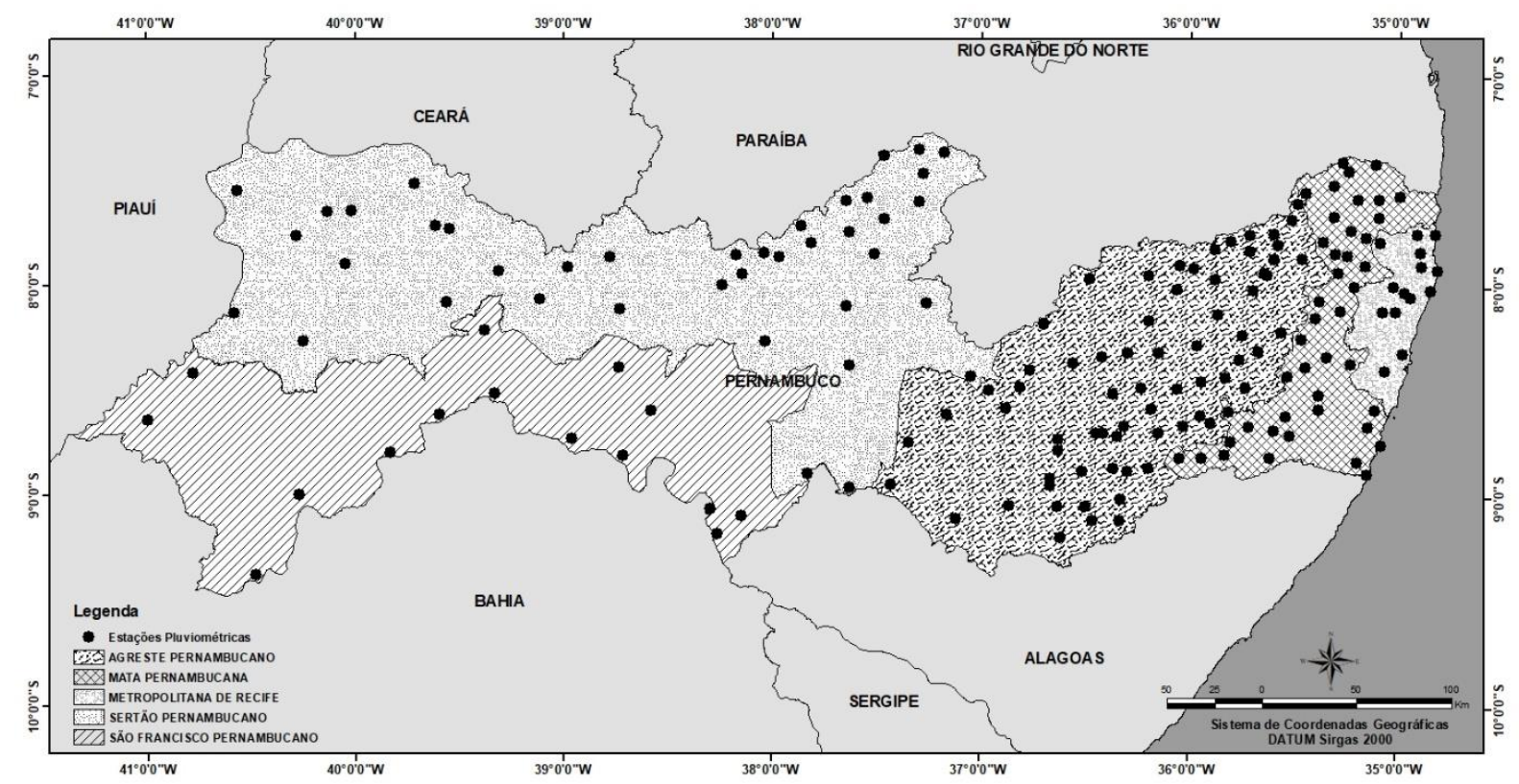

Fonte: Adelino (2019). Org.: Elaborado(a) pelo autor(a). 
De acordo com Barros et al., (2012), a região Nordeste apresenta clima semiárido associado a uma vegetação xerófita em cerca de $50 \%$ do seu território. Esse clima é caracterizado pelas irregularidades espaciais e temporais do regime de chuvas, com maior destaque nas mesorregiões do agreste e do sertão. Estudos indicam que fenômenos do tipo El Niño - Oscilação Sul (ENOS), e a circulação geral da atmosfera seriam os responsáveis pela ocorrência de baixos totais pluviométricos (MOLION, 1985; NOBRE; SHUKLA, 1996).

Quanto à vegetação, a Floresta Tropical Perene, a Floresta Tropical Semidecídua (Agreste) e a Caatinga revestem o estado. Na área de transição entre os climas tropical e semiárido há uma vegetação florestal peculiar, em que se misturam espécies da Floresta Atlântica e da Caatinga, denominada de vegetação do Agreste (BANCO DO NORDESTE, 2001). No interior, domina o Bioma da Caatinga.

Os brejos têm grande importância para a população local, sustentando grande parte da agropecuária nos períodos menos chuvosos. Na Zona da Mata e no Litoral, o clima predominante é o tropical subúmido e úmido, onde o principal período chuvoso ocorre nos meses de março a agosto. Os principais sistemas meteorológicos responsáveis pelas chuvas no estado são: 1) Zona de Convergência Intertropical (março a maio); 2) Vórtices Ciclônico em Ar Superior (novembro a fevereiro); 3) Cavado e Instabilidades de Frentes Frias (praticamente o ano todo); 4) Ondas de Leste (maio a julho); e 6) Sistemas de Brisa (praticamente o ano todo) (SOUZA, 2013).

A rede hidrográfica do estado possui como centro dispersor de águas 0 maciço da Borborema, que separa as águas que correm para o leste, para a vertente Atlântica, das que correm para o sudoeste, para a vertente do Rio São Francisco. Na parte oriental da Borborema estão os três principais rios do estado, que deságuam no Oceano Atlântico - o Capibaribe, o Ipojuca e o Una. Com algumas centenas de quilômetros de comprimento, esses rios têm o seu alto e médio curso no Agreste, onde apresentam regime temporário, enquanto no baixo curso, na região da Mata, são perenes (CEPED; UFSC, 2012).

O Rio São Francisco, no longo percurso que banha o estado, faz divisa com a Bahia. Nesta região a navegação é mínima, devido aos desníveis acentuados no leito do rio, só sendo possível apenas em pequenos trechos, com pequenas embarcações. Em Pernambuco, na estação das chuvas, correm alguns de seus 
afluentes pela margem esquerda, a exemplo do Ipanema, Moxotó, Pajeú, Garças e Brígida (ANDRADE, 2007).

\section{Metodologia}

Os dados pluviométricos das Estações Meteorológicas do Estado de Pernambuco (Figura 02) foram adquiridos juntos a APAC (Agência Pernambucana de Águas e Clima) que abrangem o período entre 1993 a 2016, sendo os valores médios de precipitação calculados com base na pluviometria dos anos dos dados disponíveis para cada munícipio, onde 39\% das estações avaliadas possuíam 23 anos de dados, $18 \%$ entre 22 a 19 anos, $17 \%$ com 18 anos de dados, $9 \%$ com 17 anos de dados e 17\% menos de 16 anos. Assim, a escolha das referidas estações, foi com o propósito de obter séries históricas completas e, ou, com menos falhas possíveis para o período de estudo.

A condição espacial da precipitação sugere sempre a necessidade de analisar os dados de conjuntos de estações de medição pluviométricas próximas para permitir o preenchimento de lacunas nos registros ou a substituição de dados observados e considerados errôneos (ANA, 2012).

Portanto, a utilização dos dados foi procedida de uma análise no tocante ao preenchimento de falhas em cada série (município a município) e consistência dos dados pluviométricos visando aprimorar o estudo e a identificação e correção de erros, bem como falhas das séries pluviométricas.

Figura 02 - Distribuição das Estações Meteorológicas no Estado de Pernambuco.

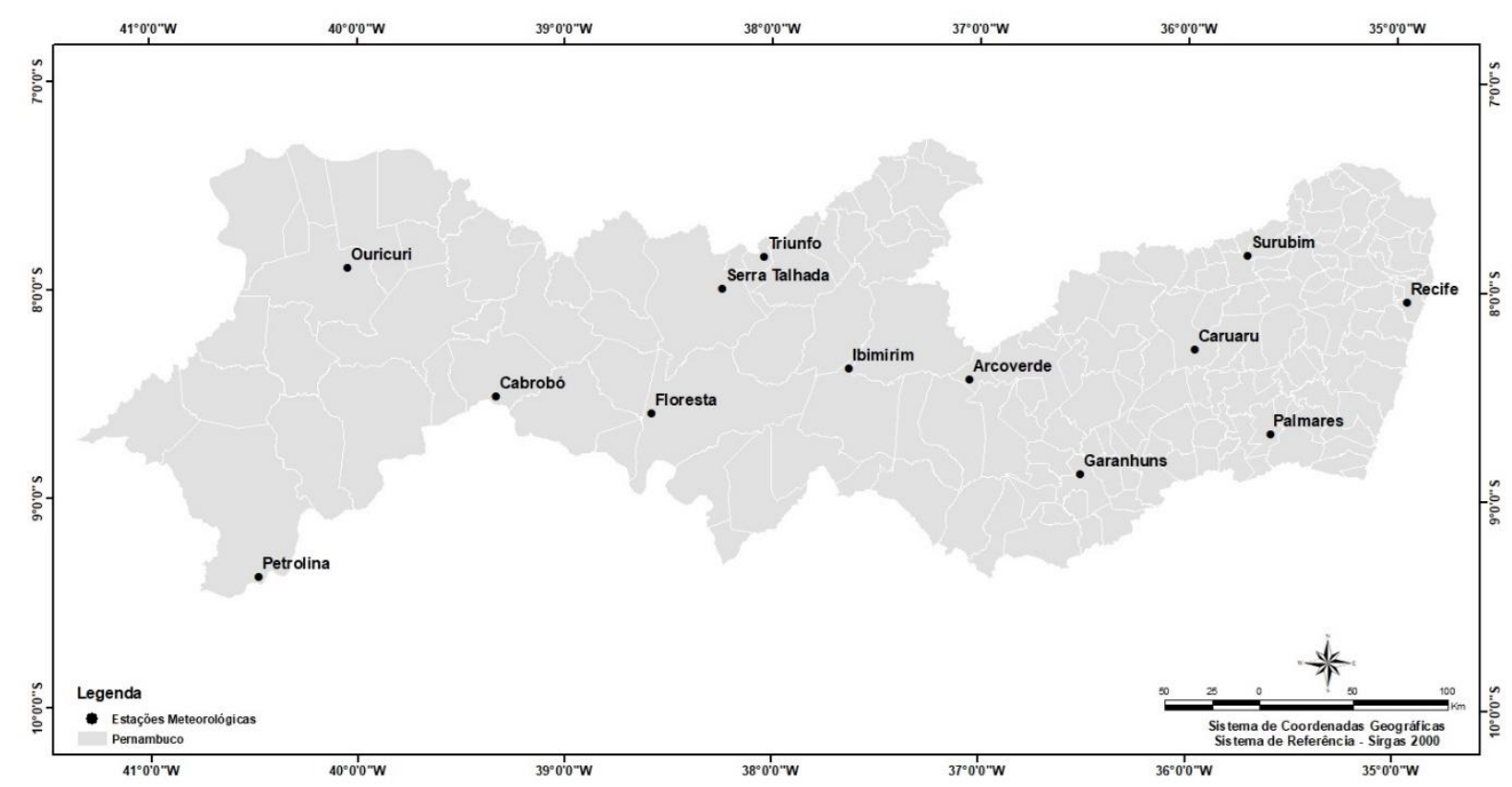

Fonte: Adelino (2019). Org.: Elaborado(a) pelo autor(a). 
Para o preenchimento de falhas foi utilizado o método de ponderação regional. Neste método são selecionados pelo menos três postos que possuam no mínimo 10 anos de dados e que se localizem em uma região climática semelhante ao posto a ser preenchido (BERTONI; TUCCI, 2001). A equação utilizada foi:

$y=\frac{1}{n}\left(\frac{x_{1}}{x_{m 1}}+\frac{x_{z}}{x_{m 2}}+\frac{x_{s}}{x_{m s}}\right) y_{m}$

Em que: y é o valor a ser preenchido, $n$ é número de pontos utilizados, $\mathrm{x}_{1}, \mathrm{x}_{2}, \mathrm{x}_{3}$ são as precipitações correspondentes ao mês ou ao ano da falhas, $y_{m}$ é a precipitação

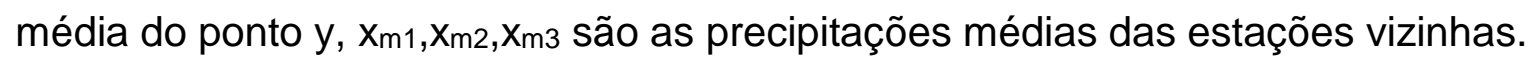

Com as falhas de preenchimento corrigidas e os dados verificados, determinou-se a precipitação média anual para cada estação pluviométrica e as médias anuais de evapotranspiração.

Os dados meteorológicos diários utilizados para a obtenção da evapotranspiração de referência diária foram: temperatura máxima, temperatura mínima, umidade relativa, velocidade do vento a $10 \mathrm{~m}$ com conversão para altura de dois metros por meio do software REF-ET (Reference Evapotranspiration Calculator Software) (ALLEN, 2016), e insolação. Para o cálculo da evapotranspiração e verificação das possíveis ausências de alguns elementos climáticos na evapotranspiração, utilizou-se da equação de Penman-Monteith (FAO) para intervalo de tempo de 24 horas.

A evapotranspiração de referência foi calculada para oito estações convencionais situadas no estado: Arcoverde, Cabrobó, Garanhuns, Ouricuri, Petrolina, Recife, Surubim e Triunfo, pelo programa Ref-ET (ALLEN, 2016). Esse programa fornece cálculos padronizados de evapotranspiração de referência para quinze dos métodos e equações mais comuns que estão atualmente em uso. Os cálculos baseiam-se nas medições de dados de tempo que são disponibilizados pelo usuário. Os dados das estações foram fornecidos pelo INMET (Instituto Nacional de Meteorologia).

A evapotranspiração de referência para os demais municípios foi calculada pelo método da interpolação, utilizando o algoritmo IDW (Inverse Distance Weighting), disponível no Sistema de Informações Geográficas (SIG) QGIS. Foi 
gerado uma imagem raster e posteriormente as isolinhas para os valores exatos de ETo, em cada município do Estado de Pernambuco.

A interpolação é o processo de utilização de pontos com valores conhecidos para estimar os valores em outros pontos desconhecidos. Existem vários métodos de interpolação, nesta pesquisa utilizou-se o método IDW (Inverse Distance Weighting), neste método os pontos de amostragem são ponderados durante a interpolação de tal forma que a influência de um ponto em relação a outro diminui com a distância do ponto desconhecido que se deseja criar. Durante o processo a ponderação é atribuída a pontos de amostragem através da utilização de um coeficiente de ponderação que controla como a influência de ponderação vai cair à medida que a distância aumenta entre os novos pontos. Quanto maior for 0 coeficiente de ponderação, menor serão os efeitos sobre os pontos, caso estejam longe do ponto desconhecido durante 0 processo de interpolação. Como 0 coeficiente aumenta, o valor do ponto desconhecido se aproxima do valor do ponto de observação mais próximo (DE VARGAS et al., 2019).

$O$ índice de aridez, indicador de susceptibilidade à desertificação, segue critérios estabelecidos pela UNESCO (United Nations Educational, Scientific and Cultural Organization, 1979), consistindo da razão entre a quantidade anual de água precipitada em uma região e a correspondente perda máxima possível de água para a atmosfera (Evapotranspiração Potencial). Portanto, o índice de aridez (IA) representa o quanto uma região é árida.

Para tanto, a determinação do índice de aridez foi realizada para os 185 municípios pertencentes ao Estado de Pernambuco. $O$ índice de aridez é dado pela Equação 2.

$I A=\frac{p_{r}}{E T_{Q}}$

$x$

100

Em que: $\operatorname{Pr}$ é a precipitação média anual, dada em milímetros, e ETo é a evapotranspiração de referência média anual, calculada pelo método de PenmanMonteith/FAO descrito em Allen et al. (1998), também em milímetros.

A classificação climática para o índice de aridez seguiu critérios estabelecidos pelo Conselho Nacional de Meio Ambiente (CONAMA, 1997), Quadro 01. 
Quadro 01 - Classes de clima de acordo com os valores do índice de aridez.

\begin{tabular}{lc}
\hline Classe & Valores de IA \\
\hline Hiper-árido & $<5,00$ \\
Árido & $05-20$ \\
Semi-árido & $21-50$ \\
Sub-úmido e seco & $51-65$ \\
Sub-úmido e úmido & $>65$ \\
\hline
\end{tabular}

Fonte: Resolução CONAMA № 238/1997.

Para a elaboração da distribuição espacial do índice de aridez total para o Estado de Pernambuco foi utilizado o sistema de informação geográfica (SIG) QuantumGIS (QGIS). A distribuição dos mapas foi definida em intervalos de cinco anos, visando uma melhor representação e disposição das informações, bem como o comportamento e variação do índice de aridez (IA) para cada região no período de 23 anos, obtendo-se, desta maneira, uma menor influência das condições climáticas.

A suscetibilidade climática à desertificação foi determinada a partir da classificação do Plano Nacional de Combate à Desertificação, de acordo com três categorias que variam conforme escala do IA (MATALLO JÚNIOR, 2003) descritos no Quadro 02:

Quadro 02 - Níveis de suscetibilidade à desertificação a partir do Índice de Aridez (IA).

\begin{tabular}{cc}
\hline Valores de IA & Suscetibilidade a Desertificação \\
\hline $05-20$ & Muito Alta \\
$21-50$ & Alta \\
$51-65$ & Moderada \\
\hline
\end{tabular}

Fonte: Matallo (2003).

\section{Resultados e Discussão}

Na Figura 3 estão apresentados a distribuição espacial e temporal do índice de aridez para o Estado de Pernambuco, nos intervalos: 1993 - 1997, 1998 - 2002, 2003 - 2007, 2008 - 2012, 2013 - 2016.

A distribuição espacial do índice de aridez mostra que mais de $50 \%$ do território de Pernambuco ficou inserido no intervalo 21,0 - 50,0, classificando-o como região semiárida (Figura 03). 
Figura 03 - Distribuição espacial e temporal do índice de aridez para o Estado de Pernambuco.

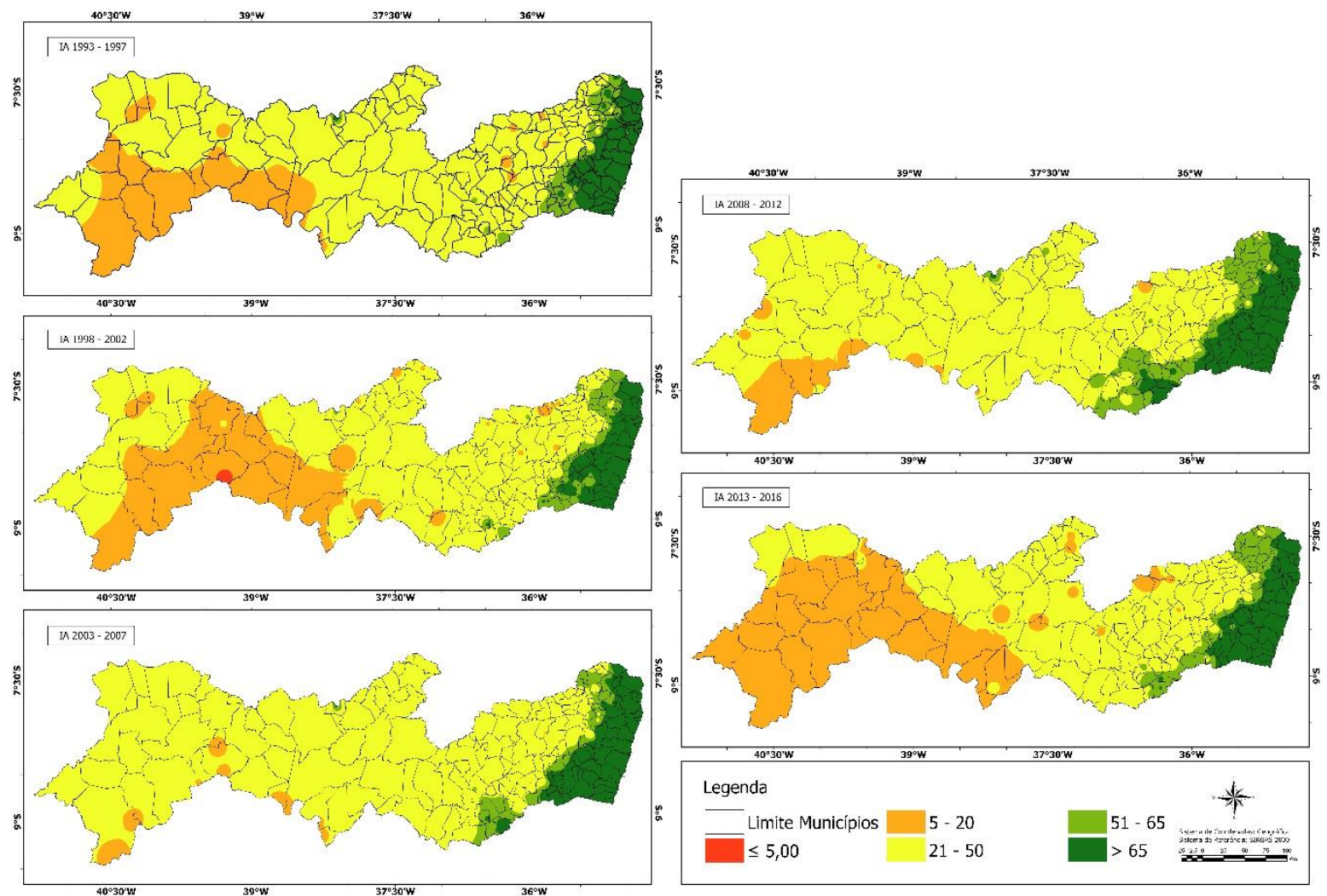

Fonte: Adelino (2019). Org.: Elaborado(a) pelo autor(a).

Observa-se também que os menores valores de índice de aridez sofreram variações consideráveis no período analisado.

Verifica-se, no intervalo de 1998 - 2002, que regiões do sertão pernambucano, passaram a registrar valores de índice de aridez compreendidos de 5,0 - 20,0 destacando os municípios de Parnamirim, Serrita, Salgueiro e Verdejante, que apresentaram baixos valores de pluviosidade e elevados valores de evapotranspiração (Quadro 03). Dados do ONI (2019), mostram que de 1998 a 2001 ocorreram eventos de La Niña, fenômeno que caracteriza-se pelo resfriamento anormal das águas do Pacífico tropical (AN; KIM, 2017) Apesar da La Niña contribuir com o aumento na frequência de intensidade das chuvas, no semiárido, a precipitação em algumas regiões é de natureza convectiva e ocorre em áreas isoladas. Segundo Freire et al. (2011) e evidenciados pelo ONI (2019) o El Niño mais forte do século foi compreendido de 1997 a 1998, a seca, provocando grandes impactos sociais, econômicos e agrários, no nordeste brasileiro. 
Quadro 03: Valores para o intervalo de 1998 - 2002, para evapotranspiração, pluviosidade e índice de aridez em algumas cidades do Estado de Pernambuco.

\begin{tabular}{cccc}
\hline Município & $\begin{array}{c}\text { Evapotranspiração } \\
(\mathbf{m m})\end{array}$ & $\begin{array}{c}\text { Pluviosidade } \\
(\mathbf{m m})\end{array}$ & $\begin{array}{c}\text { Índice de } \\
\text { Aridez }\end{array}$ \\
\hline Parnamirim & 2081,23 & 346,26 & 16,63 \\
Salgueiro & 2102,40 & 327,66 & 15,58 \\
Serrita & 2041,80 & 415,96 & 20,37 \\
Verdejante & 2027,94 & 332,24 & 16,383 \\
\hline
\end{tabular}

Fonte: Adelino (2019). Org.: Elaborado(a) pelo autor(a).

No período compreendido entre 2003 e 2007 houve um considerável aumento dos valores mínimos de aridez, que antes registravam valores entre 5,0 e 20,0, passaram a destacar valores no intervalo de 21,0 - 50,0, o que evidencia um aumento da pluviosidade. Pode-se observar também este comportamento no período de 2008 - 2012, porém em alguns pontos isolados o índice de aridez voltou a registrar valores mínimos. A redução dos valores mínimos de aridez, podem ser justificados pela influência do ENOS (EI Nino Oscilação Sul) ocorrido entre os anos de 2009 - 2011 considerado de amplitude Forte pelo ONI (2019). De acordo com Gurjão et al. (2012), existe uma relação entre a atuação do ENOS e a variabilidade no volume das chuvas na região semiárida, no entanto, sistemas atmosféricos de escala sinótica como os vórtices ciclônicos de altos níveis podem alterar substancialmente o impacto deste fenômeno favorecendo ou inibindo 0 desenvolvimento de sistemas precipitantes intensos.

Vale salientar que quanto menor for o índice de aridez, maior a capacidade de uma região em ter caráter árido. Entre os anos de 2013 - 2016, a Região do São Francisco Pernambucano apresentou os menores índices pluviométricos, com destaque para o município de Itacaruba, que registrou uma média pluviométrica, para a série histórica analisada, de $237,57 \mathrm{~mm}$, uma redução de $34,56 \%$ entre os períodos de 2008-2012 para 2013-2016 e índice de aridez de 6,1, o menor índice registrado em relação a todos os 185 municípios do Estado de Pernambuco. Ainda nesta região, ressalta-se o município de Jatobá, que apresentou também o valor pluviométrico na série histórica de 23 anos extremamente baixo, aproximadamente uma média de 263,76 mm. Minuzzi et al. (2005), afirmam que durante eventos do El Niño há a ocorrência de irregularidades na distribuição de chuvas, visto que estas 
tendem a ficar abaixo da média para a porção compreendida entre o nordeste do Estado de Minas Gerais até a porção leste da Região Nordeste.

Em contrapartida, nos períodos de 2003 - 2007 e 2008 - 2012, os altos valores de aridez mantiveram-se quase que constantes, nas regiões Metropolitana de Recife e Mata Pernambucana, com média de aridez de 120,475 e 124,649 respectivamente para os intervalos.

Deste modo, percebe-se que o IA, no estado de Pernambuco, aumenta no sentido do oeste para leste, o que indica que o clima se torna mais úmido ou menos árido a medida em que se desloca para o litoral do Estado.

No período entre 1993 - 1997, a região Metropolitana de Recife, apresentou a menor média do valor de IA com 98,52 (Tabela 01), mantendo-a na classificação Sub-úmido e úmido. Esse comportamento pode ser justificado, uma vez que, o período em destaque foi o período em que se registrou umas das maiores amplitudes do fenômeno El Niño.

Tabela 01 - Média para o índice de aridez de acordo com os intervalos estabelecidos para as Mesorregiões do Estado de Pernambuco.

\begin{tabular}{lccccc}
\hline Região & $\mathbf{1 9 9 3}$ & $\mathbf{1 9 9 8}$ & $\mathbf{2 0 0 3}$ & $\mathbf{2 0 0 8}$ & $\mathbf{2 0 1 3}$ \\
& $\mathbf{1 9 9 7}$ & $\mathbf{2 0 0 2}$ & $\mathbf{2 0 0 7}$ & $\mathbf{2 0 1 2}$ & $\mathbf{2 0 1 6}$ \\
\hline \multicolumn{5}{c}{ Média (IA) } \\
\hline Metropolitana de Recife & 98,523 & 101,650 & 120,475 & 124,649 & 110,637 \\
Mata Pernambucana & 64,113 & 76,048 & 73,780 & 76,834 & 67,177 \\
Agreste Pernambucano & 33,226 & 38,883 & 39,364 & 45,989 & 36,811 \\
São Francisco Pernambucano & 18,455 & 15,987 & 23,341 & 22,653 & 13,449 \\
Sertão Pernambucano & 28,345 & 22,902 & 36,114 & 34,928 & 24,321 \\
\hline
\end{tabular}

Fonte: Adelino (2019). Org.: Elaborado(a) pelo autor(a).

As maiores variações do índice de aridez foram observadas na região do São Francisco Pernambucano, com valores variando entre 15,98 e 13,44 nos períodos 1998-2002 e 2013-2016, respectivamente, classificando a região como semiárida.

Analisando a susceptibilidade a desertificação, observa-se na Figura 04 o balanço global do índice de aridez e a classificação das regiões do Estado de Pernambuco em níveis de susceptibilidade. 
Figura 04 - Distribuição espacial da susceptibilidade a desertificação global para o Estado de Pernambuco.

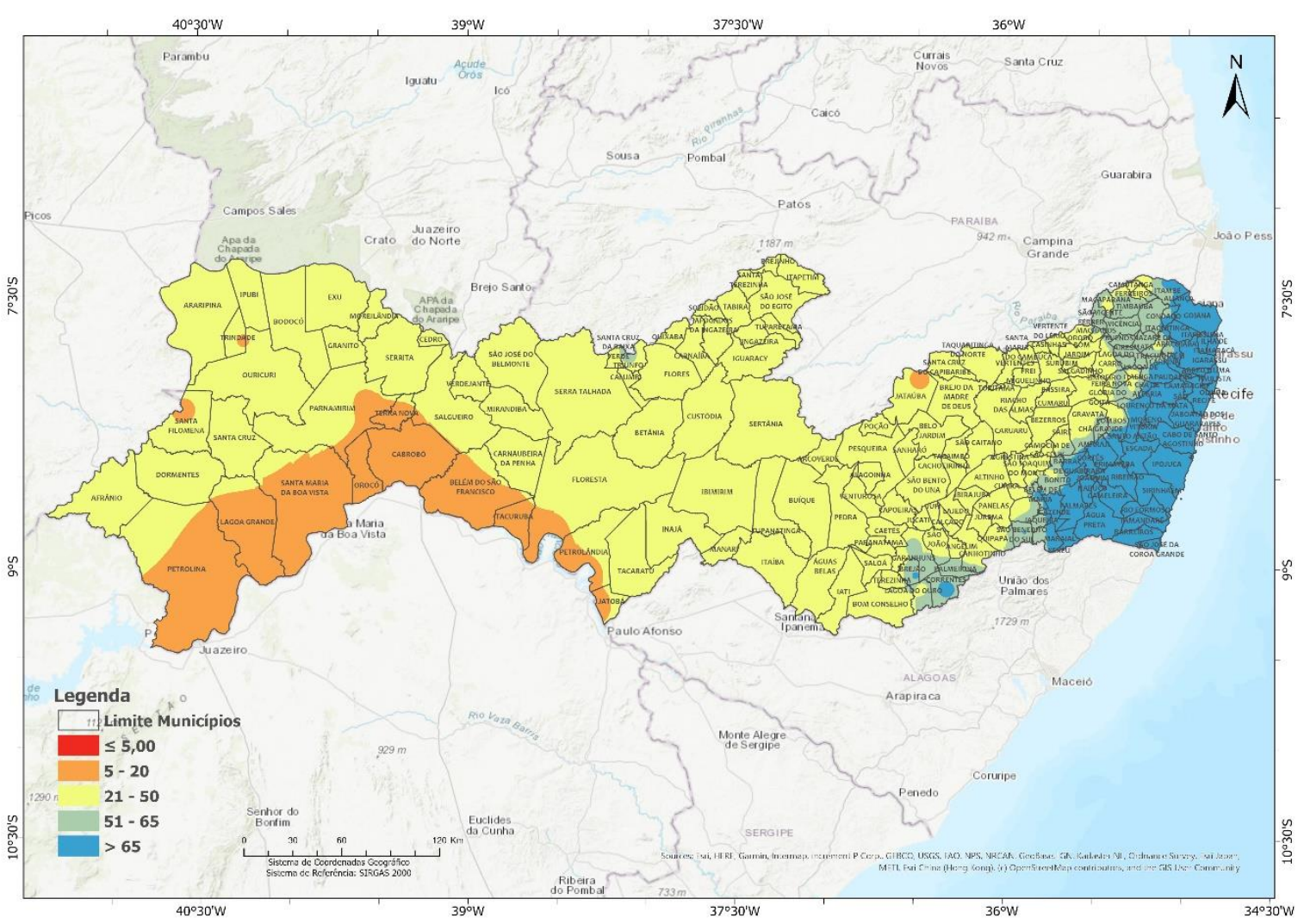

Fonte: Adelino (2019). Org.: Elaborado(a) pelo autor(a).

De acordo com Schenkel e Matallo Júnior (2003), quanto maior for a capacidade de uma região em apresentar características áridas maior sua predisposição a desertificação. Neste contexto, observa-se que a região do São Francisco Pernambucano encontra-se em alerta, ou seja, com maiores probabilidades de ocorrer desertificação, com destaque para os municípios de Petrolina $(I A=15,68)$, Lagoa Grande $(I A=16,36)$, Santa Maria da Boa Vista $(I A=17,78)$, Orocó $(I A=14,32)$, Cabrobó $(I A=13,89)$, Terra Nova $(I A=16,96)$, Belém do São Francisco $(I A=16,11)$ e Itacuruba $(I A=11,65)$, quando comparados com a região Metropolitana de Recife, que não apresenta risco a desertificação, alçando índices maiores que 65,0, como pode ser observado para o município de Recife que apresenta valor de índice de aridez de aproximadamente 113,81. Lacerda et al. (2016), afirmam que $80 \%$ do espaço geográfico do estado de Pernambuco é predominantemente semiárido. No extremo oeste, a precipitação acumulada, em média, é inferior a $700 \mathrm{~mm} / \mathrm{ano}$, setor que abrange as mesorregiões do Sertão do São Francisco, de Petrolina, até Araripina, tendo como principal período chuvoso os meses de janeiro a abril sempre afetado por secas e enchentes. Santos et al. (2017), 
ao analisarem as projeções do IA para o estado de Pernambuco de 2010 a 2099, verificaram que no século XXI, todo o estado de Pernambuco poderá está inserido como semiárido. Condição esta que, muito provavelmente, trará muita perda da biodiversidade na região metropolitana do Recife, agreste e mata pernambucana.

O aumento das condições de aridez de forma precoce para Cabrobó pode estar associado a uma antecipação do aumento da temperatura do ar, evapotranspiração potencial e índice de aridez, e redução dos índices de umidade e hídrico, aumentando o saldo negativo das regiões mais áridas, que ocorreriam próximo ao ano de 2050 e 2100 (SANTOS et al., 2010).

De acordo com a distribuição temporal, o índice de aridez para os intervalos analisados, apresentou diferentes variações para todo o estado de Pernambuco, ocorrendo alterações mais abruptas nas regiões do Sertão Pernambucano e São Francisco Pernambucano. As regiões que apresentaram oscilações, baixos valores e, posteriormente, exibiram aumento no índice de aridez, pode ser justificado pelas variações nos acúmulos de pluviosidade nos períodos analisados.

O município de Itacuruba teve destaque por apresentar o menor valor do índice de aridez em todo o período analisado $(11,25)$, entre todos os municípios analisados, passando assim a apresentar também a maior susceptibilidade a desertificação. Uma pequena área da Mesorregião do Agreste Pernambucano, no município de Jataúba, também registrou valor de IA muito baixo, quando comparado com os demais da Mesorregião $(17,77)$, classificando-o como muito alto grau de suscetibilidade para desertificação. Este município não apresentou influência de estações meteorológicas vizinhas, uma vez que as estações próximas obtiveram IA superior a 20, classificando-os em alto grau de susceptibilidade.

De acordo com Lopes et al. (2017), a região Semiárida do Nordeste do Brasil apresenta tendências estatisticamente significativas de aumento nas condições de aridez.

Marengo e Bernasconi (2015), investigaram o risco a desertificação em regiões semiáridas do Nordeste brasileiro, por meio do índice de aridez e verificaram a extensão das áreas com condições semiáridas e áridas no presente e para o futuro até o ano de 2100. Concluíram que, de acordo com as projeções regionais de mudanças climáticas, haverá um aumento da secura na região, com reduções de chuvas, aumento de temperatura e déficits de água e períodos de seca mais longos, levando a seca e condições áridas que preveem na segunda metade do século 21. Diante deste aspecto, os autores esperam que as áreas com condições áridas 
cresçam para cobrir áreas atualmente com condições subsumidas secas e que se tornem maior até 2100. Esse aumento na aridez, combinado com a degradação da terra, com o mau uso do solo, com a retirada da vegetação nativa, pode aumentar o risco de desertificação (SILVA et al., 2011).

\section{Conclusões}

No período de 2013 a 2016 o Estado de Pernambuco sofreu grandes reduções dos valores do índice de aridez, assim como em suas respectivas pluviosidades, com destaque para o município de Itacaruba que apresentou o menor índice de aridez $(6,1)$, e a maior susceptibilidade a desertificação com grau de 11,25.

Uma pequena área do município de Jataúba, pertencente a região do Agreste Pernambucano, foi classificado como muito alto para o nível de susceptibilidade, sendo informações de grande importância para o a gestão ambiental, bem como ações de políticas públicas e tomadas de decisões em relação as interações dos recursos hídricos.

O resultado da análise da tendência climática à desertificação indicou a suscetibilidade para aproximadamente $80 \%$ do território geográfico do Estado, com destaque para as mesorregiões do Sertão Pernambucano e São Francisco Pernambucano, indicando que as regiões possuem elevadas disposições em tornarem-se áreas com grande processo de desertificação.

\section{REFERÊNCIAS}

ALLEN. Ref - ET Software. 2016. Disponível em: <https://www.uidaho.edu/cals/kimberlyresearch-and-extension-center/research/water-resources/ref-et-software>.

ALLEN, R. G.; PEREIRA, L.S.; RAES, D.; SMITH, M. Crop evapotranspiration guidelines for computing crop water requirements. In: FAO. Irrigation and Drainage. Paper; 56, Rome, 1998.

AMARAL, V. P.; MORAES, J. D. S.; COSTA, J.; SANTIAGO, A. Estimativa de suscetibilidade à desertificação por meio dos índices de aridez aplicados no município de Petrolina-PE. In: Embrapa Amazônia Oriental-Artigo em anais de congresso (ALICE). In: SEMINÁRIO DE INICIAČ̃̃O CIENTÍFICA, 18.; SEMINÁRIO DE PÓS-GRADUACẼ̃ DA EMBRAPA AMAZÔNIA ORIENTAL, 2., 2014, Belém, PA. Anais[...] Belém, PA: Embrapa Amazônia Oriental, 2014.

AN, SOON-IL; KIM, JI-WON. Role of nonlinear ocean dynamic response to wind on the asymmetrical transition of El Niño and La Niña. Geophysical Research Letters, [s.I.], American Geophysical Union (AGU). v. 44, n. 1, p.393-400, 2017. 
ANA. Agência Nacional de Águas (Brasil). Orientações para consistência de dados pluviométricos / Agência Nacional de Águas; Superintendência de Gestão da Rede Hidrometeorológica. Brasília: ANA, SGH, 2012. Disponível em: $<$ http://arquivos.ana.gov.br/infohidrologicas/cadastro/OrientacoesParaConsistenciaDadosPlu viometricos-VersaoJul12.pdf. > Acesso em: 2 mar. 2020.

ANDRADE, M. C O. Pernambuco e o trópico. Revista do Instituto de Estudos Brasileiros, n. 45, p. 11-20, 2007.

APAC, Agência Pernambucana de Águas e Clima, Monitoramento Pluviométrico. Disponível em: http://www.apac.pe.gov.br/. Acesso em: 23 nov. 2018.

BANCO DO NORDESTE. Portal do Banco do Nordeste. Perfil dos estados: Pernambuco, fisiografia e recursos naturais. Pernambuco: Banco do Nordeste, 2001.

BARROS, A. H. C.; ARAÚJO FILHO, J. C.; SILVA, A. B.; SANTIAGO. G. A. C. F. Climatologia do Estado de Alagoas. Boletim de Pesquisa e Desenvolvimento. n. 211. Recife: Embrapa Solos, 2012.

BERTONI, J. C.; TUCCI, C. E. M. Precipitação. In. TUCCI, C.E.M.

(Org.) Hidrologia: ciência e aplicação. 2.ed. Porto Alegre: Universidade Federal do Rio Grande do Sul, p.177-242, 2001.

BRASIL, MINISTÉRIO DO MEIO AMBIENTE DOS RECURSOS HÍDRICOS E DA AMAZÔNIA LEGAL. Convenção das Nações Unidas de combate à desertificação nos países afetados por seca grave e/ou desertificação, particularmente na África. Brasília: Plano Nacional de Combate a Desertificação, 2ª edição. 1998.

BRASIL, RESOLUÇÃO CONAMA no 238, de 22 de dezembro de 1997. Política Nacional de Controle da Desertificação. Publicada no D.O.U. em 23 de dezembro de 1997.

CGEE, CENTRO DE GESTÃO E ESTUDOS ESTRATÉGICOS - CGEE. Relatório Anual de 2016. < https://www.cgee.org.br/documents/10182/1988858/Rel_Anual_2016.pdf > Acesso em: 27 jan. 2017. 2016

COSTA NETO, F. A.; MEDEIROS, R. M.; SOUSA, E. P.; OLIVEIRA, R. C. S. Balanço hídrico como planejamento para a cidade de Olivedos-PB. In: Congresso Técnico Científico da Engenharia e da Agronomia, CONTECC, 71.2014, Anais[...] Teresina-PI, 2014.

DE VARGAS, T., GOMES, M. G., BELLADONA, R., ADAMI, M. V. D. Aplicação do Interpolador IDW para Elaboração de Mapas Hidrogeológicos Paramétricos na Região da Serra Gaúcha. Scientia cum Industria, v. 6, n.3, p.38-43, 2019.

DOMINGUES, E. P.; MAGALHÃES, A. S., RICARDORUIZ, R. M. Cenários de mudanças climáticas e agricultura no Brasil: impactos econômicos na região Nordeste. Revista Econômica do Nordeste, v. 42, n. 2, p. 229-246, 2011.

FREIRE, J. L. M.; LIMA, J. R. A.; CAVALCANTI, E. P. Análise de Aspectos Meteorológicos Sobre o Nordeste do Brasil em Anos de El Niño e La Niña. Revista Brasileira de Geografia FÍsica, Recife,v. 4, n. 3, p.429-444, 2011.

Oceanic Niño Index (ONI). ENSO Years based on Oceanic Niño Index (ONI). Disponível em: <http://ggweather.com/enso/oni.htm> Acesso em: 28 fev. 2020.

GURJÃO, C. D. S.; CORREIA, M. F.; CHAVES FILHO, J. B.; ARAGÃO, M. R. S. Influência do Enos (El Niño-Oscilação Sul) no Regime Hidrológico do Rio São Francisco: uma Análise em Regiões com Fortes Pressões Antrópicas. Revista Brasileira de Geografia Física. v. 5, n. 04, p. 774-790, 2012. 
IBAÑEZ, J., VALDERRAMA, J. M., PAPANASTASIS, V., EVANGELOU, C., PUIGDEFÁBREGAS, J. A multidisciplinary model for assessing degradation in Mediterranean rangelands. Land Degradation \& Development, v. 25, n. 5, p. 468-482, 2014.

IBGE. Instituto Brasileiro de Geografia e Estatística. Disponível em: < https://cidades.ibge.gov.br/brasil/pe/panorama> Acesso em: 08 de mai 2017. 2011

LACERDA, F. F, NOBRE, P.; CARMO SOBRAL, M.; LOPES, G. M. B. Alterações climáticas globais; uma realidade em Pernambuco. Anais da Academia Pernambucana de Ciência Agronômica 11, Anais[...], 121-154, 2016.

LANFREDI, M., COPPOLA, R., SIMONIELLO, T., COLUZZI, R., D'EMILIO, M., IMBRENDA, V., MACCHIATO, M. LANFREDI, MARIA ET AL. Early identification of land degradation hotspots in complex bio-geographic regions. Remote Sensing, v. 7, n. 6, p. 8154-8179, 2015.

LOPES, I; DOS SANTOS, S. M.; LEAL, B. G.; MELO, J. M. M. Variação do índice de aridez e tendência climática à desertificação para a região semiárida do nordeste brasileiro. Revista Brasileira de Geografia Física, v. 10, n. 4, p. 1014-1026, 2017.

MARENGO, J. A., BERNASCONI, M. Regional differences in aridity/drought conditions over Northeast Brazil: present state and future projections. Climatic Change, v. 129, n. 1-2, p. 103-115, 2015.

MATALLO JUNIOR, H. A desertificação no mundo e no Brasil. Desertificação. Brasília: UNESCO. 2003.

MATALLO JUNIOR, H. Indicadores de Desertificação: histórico e perspectivas. Brasília: UNESCO, 2001.

MEDEIROS, R. M. Mudanças do ENSO com relação à precipitação e dias com chuva em Recife - PE, Brasil. Revista Mirante, Anápolis (GO), v. 11, n. 8, P. 222-240, 2018.

MINUZZI, R. B.; SEDIYAMA, G. C.; RIBEIRO, A.; COSTA, J. M. N. EI Niño: ocorrência e duração dos veranicos do Estado de Minas Gerais. Revista Brasileira de Engenharia Agrícola e Ambiental, v. 9, n. 3, p. 364-371 [online]. 2005. Disponível:

http://dx.doi.org/10.1590/S141543662005000300011. Acesso: 08 de mai 2017.

MOLION, L. C. B. Seca, o eterno retorno. Ciência Hoje, v. 3, n. 18, p. 26-32, 1985.

NOBRE, P.; SHUKLA, J. Variations of sea surface temperature, wind stress, and rainfall over the tropical Atlantic and South America. Journal of climate, v. 9, n. 10, p. 2464-2479, 1996.

OLIVEIRA, R.C.S.; MEDEIROS, R.M. DE; COSTA NETO, F. A.; GOMES FILHO, M.F. Estudo das oscilações da temperatura máxima do ar e precipitação em Lagoa Seca-PB visando mudanças climáticas. In: VI Workshop de Mudanças Climáticas e Recursos Hídricos do Estado de Pernambuco e III Workshop Internacional sobre Mudanças Climáticas e Biodiversidade, Anais[...], Recife. 2014.

PENMAN, H.L. The physical bases of irrigation control. In: Hort. Congr., 2, London, Royal Horticultural Society, p.913-924, 1953.

QGIS. Interpolation Surface in QGIS Saptial Analysis. 2014. Disponível em: https://docs.qgis.org/2.2/en/docs/gentle gis introduction/spatial analysis interpolation.html.

SAMPAIO, E. V. S. B; SAMPAIO, Y. Desertificação: conceitos, causas, consequências e mensuração. Recife, Universidade Federal de Pernambuco, 2002. 
SANTOS, N.D.; SILVA, V. P. R.; SOUSA, F. A. S.; SILVA, R. A. Estudo de alguns cenários climáticos para o Nordeste do Brasil. Revista Brasileira de Engenharia Agrícola e Ambiental. V.14, n.5, p.492-500, 2010.

SANTOS, T. S.; CASTRO, A. A.; SILVA, A. R.; QUEIROZ, D. E.; DA SILVA, T. G. F. Projeção da suscetibilidade a desertificação em Pernambuco utilizando o modelo HADGEMES. Revista Brasileira de Geografia Física, v.10, n.04, p. 1170-1179, 2017.

SCHENKEL, C. S.; MATALLO JÚNIOR, H. Desertificação. 2. ed. Brasília: UNESCO, 2003.

SILVA, V.P.R.; PEREIRA, E.R.R.; AZEVEDO, P.V.; SOUSA, F.A.S.; SOUSA, I.F. Análise da pluviometria e dias chuvosos na região Nordeste do Brasil. Revista Brasileira de

Engenharia Agrícola e Ambiental, Campina Grande, v. 15, n. 2, p. 131-138, 2011.

SOUZA, I. A. Variabilidade climática e deficiência hídrica na bacia do Una, PE e sua relação com as anomalias de temperaturas dos oceanos Pacífico e Atlântico. Recife, 2013. 102 f. Tese (doutorado) - UFPE, Centro de Tecnologia e Geociências, Programa de Pós-graduação em Tecnologias Energéticas e Nucleares, 2013.

UNESCO. United Nations Educational, Scientific and Cultural Organization. Map of the world distribution of arid regions: Map at scale 1:25,000,000 with explanatory note. MAB Technical Notes 7, Paris, 54 p, 1979.

UNITED NATIONS ENVIRONMENT PROGRAMME (UNEP). Status of desertification and implementation of the United Nations plan of action to combat desertification. Nairobi, 1992.

UNIVERSIDADE FEDERAL DE SANTA CATARINA (UFSC). CENTRO UNIVERSITÁRIO DE ESTUDOS E PESQUISAS SOBRE DESASTRES (CEPED). Atlas Brasileiro de Desastres Naturais: 1991-2010. Vol. Brasil. Centro Universitário de Estudos e Pesquisas sobre Desastres. Florianópolis: CAD UFSC, 2012. Disponível: http://www.ceped.ufsc.br/biblioteca. Acesso em: 09 jun. 2018.

ZDRULI, P. Land resources of the Mediterranean: status, pressures, trends and impacts on future regional development. Land Degradation \& Development, v. 25, n. 4, p. 373-384, 2014.

\section{NOTAS DE AUTOR}

\section{CONTRIBUIÇÃO DE AUTORIA}

Michelle Adelino Cerqueira - Concepção. Coleta de dados, Análise de dados, Elaboração do manuscrito, revisão e aprovação da versão final do trabalho

Flávia Mazzer Rodrigues - Concepção e elaboração do manuscrito. Participação ativa da discussão dos resultados; Revisão e aprovação da versão final do trabalho.

Gleymerson Almeida- Elaboração do manuscrito. Participação ativa da discussão dos resultados; Revisão e aprovação da versão final do trabalho.

\section{FINANCIAMENTO}

Não se aplica.

CONSENTIMENTO DE USO DE IMAGEM

Não se aplica.

APROVAÇÃO DE COMITÊ DE ÉTICA EM PESQUISA

Não se aplica. 


\section{LICENÇA DE USO}

Este artigo está licenciado sob a Licença Creative Commons CC-BY. Com essa licença você pode compartilhar, adaptar, criar para qualquer fim, desde que atribua a autoria da obra.

\section{HISTÓRICO}

Recebido em: 24-04-2018

Aprovado em: 13-05-2020 